\title{
Enabling Valuation of Nutrition Integration into MBBS Program
}

\author{
Niikee Schoendorfer and Jennifer Schafer \\ Discipline of Medical Education, School of Medicine, University of Queensland, Mayne Medical Building, Herston, QLD 4006, Australia \\ Correspondence should be addressed to Niikee Schoendorfer; n.schoendorfer@uq.edu.au
}

Received 13 November 2014; Revised 2 April 2015; Accepted 9 April 2015

Academic Editor: Rose Ann DiMaria-Ghalili

Copyright (c) 2015 N. Schoendorfer and J. Schafer. This is an open access article distributed under the Creative Commons Attribution License, which permits unrestricted use, distribution, and reproduction in any medium, provided the original work is properly cited.

\begin{abstract}
Good nutrition is the foundation for good health. While basic nutritional assessment is part of many medical consultations, it remains underutilized despite becoming increasingly recognized as important for chronic disease prevention and management. Many studies identify shortfalls in physicians' knowledge and attitudes toward nutrition as a result of inadequate emphasis in medical school. Additional teaching about nutrition and nutritional assessment procedures was integrated within a first year module of a MBBS program. Blended learning techniques were employed to facilitate student engagement and sessions were evaluated via student response system technology (clickers) or minute paper feedback. The initial survey to all medical students $(n=1037)$ documented that less than half $(45 \%)$ felt they could discuss nutrition with patients. The majority $(n=606)$ regularly consulted the internet for nutrition information, while only 163 utilised peer-reviewed journals. With the first year cohort $(n=297)$ "clickers" revealed that $91 \%$ felt nutrition important to health care and $82 \%$ felt it important in general practice. $71 \%$ found using clickers an interesting enhancement, whilst $70 \%$ noted the nutrition content informative. Early nutrition teaching was well received by students. Long-term increases in nutritional information dissemination, particularly by influential health care workers, might benefit not only economies but also the health of society as a whole.
\end{abstract}

\section{Introduction}

Nutrition assessment and advice are underutilized in medical practice despite becoming recognized as increasingly vital [1]. The rise of chronic diseases such as type 2 diabetes and cardiovascular disease may be attributed to long-term poor diet and lifestyle choices. In 2000 more than half of the 10 leading causes of death in the USA were associated with poor dietary intake [2]. General practitioners are the first point of contact to address patients' needs and concerns, including that of nutrition and dietary advice. A large consumer telephone survey was conducted in the Netherlands in order to ascertain public preference and perceived expertise of 11 different sources of nutritional information. Results indicated that primary care physicians scored the highest (36\%) with respondents choosing physicians for nutrition information above both dieticians (21\%) and the Food and Nutrition Education Bureau (17\%); despite only ranking $3 r d$ in level of perceived expertise, primary care physicians ranked the highest as public preference to receive nutritional advice [3]. Despite sometimes large differences in health systems and medical education methods internationally, the same barriers to the provision of nutrition services and nutrition education appear to exist.

In 1985 a nationwide survey in the USA was conducted to assess the extent of physicians providing nutritional information, which resulted in a total less than $30 \%$ indicating their use of nutrition in patient treatment plans [4]. As a result, the US Department of Health and Human Services issued a national objective to increase the number of physicians providing nutritional screening or education to their patients [5]. In 1992 a follow-up survey demonstrated only a slight increase in numbers to less than 35\% [6]. Over the years similar reports have been presented which have led to increased calls for emphasis on and reform of nutrition education of physicians [7]. The US governments Healthy People 2010 objectives identified this deficit and included a target goal of $75 \%$ of physicians offering nutrition counselling to the 
majority of their patients [8]. Today in their Healthy People 2020 Topics and Objectives, physicians providing nutritional and dietary counselling are still a priority [9].

The only national guidelines in Australia on nutritional topics which should be covered during medical education were published over 20 years ago by the National Health and Medical Research Council and there are no current guidelines in this area. Considering the exponential rate of discovery through research, particularly in the health sector over the past decade, the significance placed on nutritional information and its dissemination should be addressed. The Australasian Medical Council (AMC) does however encourage medical schools to provide teaching and learning strategies which address a number of objectives relating to knowledge and understanding of nutritional therapies. This AMC document also highlights that Medical Board guidelines encourage doctors to present all information available to allow patients to make informed choices relating to their management [10].

Literature surrounding small group activities has shown numerous positive outcomes such as higher academic achievement [11] and self-esteem [12], increased positive attitudes toward the subject area studied, greater persistence and acceptance of differences among peers, and greater retention across a wide range of educational settings [13]. While interacting with classmates, students are met with a variety of ideas from peers and have the responsibility of comparing, contrasting, and criticizing these ideas for themselves. Active learning, such as this, is much more like life-long learning than the mere recital of lecture content [14].

To benefit the students, lectures should contain interactive components and should not be entirely passive. Learning has been shown to be more permanent and meaningful when students take a more active role in the process [15]. Schlechty outlined the criteria for what he terms educational design qualities, based on the premise that when learning activities are created using this criterion, the students will be more likely to engage in their work, persevere, and find satisfaction within it. These qualities include activities which improve formative feedback, as well as those designed to encourage cooperative action between students and their peers. In order to achieve good educational practice, given tasks were varied and required that students acquire new skills, as well as different approaches, presentation styles, and modes of analysis [16].

This project set out to assess students' perceptions of the value of nutrition and a range of interactive and innovative teaching practices, including small group learning on improving student's knowledge and skills in the area of nutrition. Evaluation tools and other classroom assessment techniques were also utilized to increase student engagement and knowledge retention, as well as gain feedback [17]. The lectures also contained interactive components for students to take a more active role in their learning process [15]. Blended learning tools such as a variety of online resources, such as links to government public health and nutrition program support websites, health organization, and other credible and nutritionally relevant materials (Appendix), alongside the interactive lecture formats, were made accessible to students.
With increasing international support for the development of integrated nutrition curricula in medical schools, it is essential to evaluate the impact and assess its outcomes, while continuing to improve teaching and learning methods as action research cycles. The aim of this project was to evaluate students' perceptions of nutrition and the use of a variety of blended learning techniques, to enhance medical student's engagement and clinical practice development in relation to nutrition education in the first year Bachelor of Medicine and Bachelor of Surgery (MBBS) students.

\section{Materials and Methods}

At the outset of the project a school wide survey was also conducted to ascertain attitudes and perceived nutritional knowledge of all current medical students years 1-4 at the University of Queensland (UQ) $(n=1037)$. Relevant faculty members were also engaged and requested to provide details for where in each of their courses nutrition content was included.

First year medical students $(n=297)$ participated in an add-on series of 2 small group interactive nutritionally based educational sessions, integrating with their existing Gastrointestinal/metabolism module which spans 5 weeks and includes 54 other educational components. The initial session delivered over weeks 2 and 3 of the module comprised an overview of nutrition as possessing both nutritive and pharmacological properties, as well as the current state of evidence relating to the function and uses of probiotics. The second half of the first 2-hour session included a practical component, where students completed their own nutrition assessments. The second session was delivered to small groups at the conclusion of the Gastrointestinal/metabolism module. This session was composed of both evidence-based research information and practical role-playing components, to tie in the theory delivered over both sessions. Learning revolved around nutritional causes and potential treatments, as well as the biochemical mechanisms of action in relation to obesity and type II diabetes, with emphasis placed on utilizing primary research literature. Students were not required to do any preparation prior to the sessions.

This preliminary session was blended with the use of student response systems "clickers" not only to gain feedback from the students at the session's conclusion, but also to assist them in summarizing important points throughout the lecture content.

Nutritional assessments in both sessions were completed using modified versions of REAP and WAVE tools [18]. These tools have been developed by Brown University, USA, and were adapted with permission into Australian standards. The REAP or Rapid Eating Assessment for Patients is a food frequency questionnaire, which can be filled out by patients while they are in the waiting room. The REAP tool is designed to allow immediate recognition of any nutritional issues at a glance and hence is feasible for use in the general practice setting. The WAVE or weight, activity, variety, and excess tool is a desktop flash type card with key inquiries on one side and recommendations on the other. 
The second session was presented as role-play case studies utilizing the WAVE and REAP tools, in a 20-minute consultation style format. A variety of patient information tools were also provided to be used as an adjunct during the consultation. In pairs the students took turns at being the patient and physician with a concluding facilitated whole group discussion. A proportion of the groups were also video-taped and reviewed by the students for reflection, which may assist students in gauging their own progress and methods of enquiry.

Minute papers, by Angelo and Cross, were used on completion of these sessions asking "What was the most important thing learned in the class?," "What important questions remain unanswered?," and "Are there any improvements you could suggest for this session?" Students were provided with small pieces of paper outlining the above questions along with space for their brief responses. This method enables session evaluation in a very short time period and engenders no further participant burden. These authors have designed a number of classroom assessment techniques (CATs) as a type of simple evaluation utilized to collect data on student learning, with the aim of improving it. They are designed to gain feedback and assist teachers in finding out what and how well students are learning [17].

\section{Results}

The initial school wide survey administered to all medical students $(n=1037)$ documented that less than half $(45 \%)$ of the students felt they knew enough about nutrition to counsel patients. Interestingly the majority of students $(n=606)$ regularly consulted the internet for information about nutrition, while only 163 utilised peer-reviewed journals. The remaining results of this component are currently under analysis.

Participating students $(n=297)$ responses with the "clickers," utilised during the first sessions, revealed that $91 \%$ felt nutrition was important to health care and $82 \%$ felt it is important in general practice (Figure 1). $71 \%$ of the students found using the clickers to be an interesting enhancement to the session (Figure 2), whilst 70\% noted the nutrition content to be informative.

When asked about their preferred choice of "junk" food or vegetables snacks, students responded with $54 \%$ and $46 \%$, respectively. When asked about the one which they would be more likely to choose, responses were $51 \%$ and $49 \%$. The main driving force for their consumption was based on taste (38\%), availability (26\%), and price (20\%), followed, then, by health $(15 \%)$ and peers $(2 \%)$.

In relation to the multiple choice questions which appeared periodically throughout the session, the majority of students were able to answer correctly. When asked "Which micronutrient assists in both immune function and tissue synthesis" $72 \%$ of students correctly answered Vitamin C. In response to the question "Which most accurately describes factors which determine nutrient needs" $85 \%$ identified absorption, metabolism, and excretion, as well as food intake and underlying disease, as had been discussed during the session.

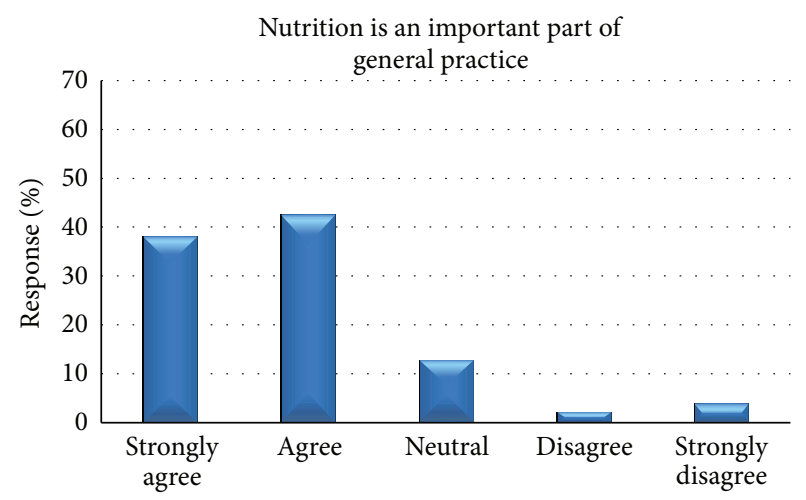

FIGURE 1: Clicker response system result from first series session.

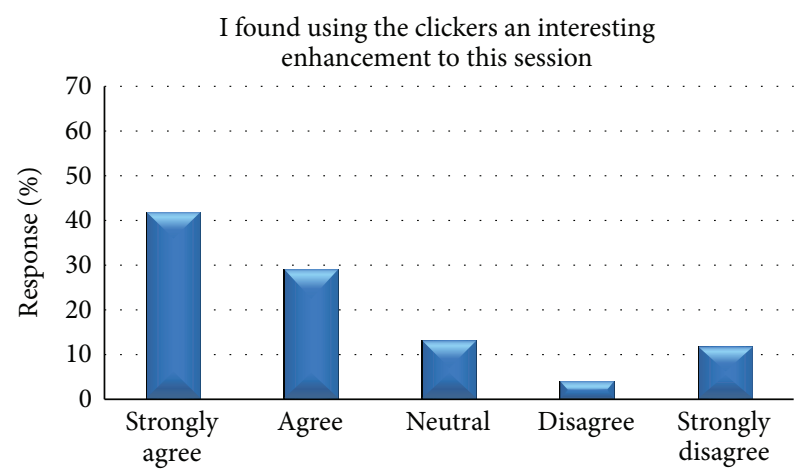

FIGURE 2: Clicker response system result from first series session.

For the second series of sessions $68 \%$ of students felt they would utilise the nutritional assessment tools if they were in general practice, while $12 \%$ were opposed and $20 \%$ unsure (Figure 3).

Students' qualitative feedback on the educational sessions is outlined in Table 1. Major emerging themes included some students recommending further lecture time to enhance their understanding of the underlying biochemical mechanisms of nutritional interventions, whilst others indicated that more practice at nutritional consulting would be beneficial. The sessions were overall well received with more students preferring practical components over theory.

\section{Discussion}

In phase I of the UQ MBBS program, students receive approximately 7 hours of formal nutrition education not including the informal learning within PBL groups, as informed by relevant faculty. In phase II, nutrition is thought to be considered where appropriate; however there is no standard to ensure this is being completed. In light of this, the introduction of increased nutrition components is being investigated to address this shortfall, beginning with phase I of the program.

With almost half of the entire student cohort from years 14 documenting insufficient knowledge to mention nutrition to patients, the limited training provided may be a causal factor in the lack of nutritional assessment and advice utilized in 
TABLE 1: Students' feedback when asked, "Are there any improvements you could suggest for the session?"

\begin{tabular}{|c|c|c|}
\hline Session & Overall theme & Selection of quotes \\
\hline $\begin{array}{l}\text { Part 1: interactive } \\
\text { lecture }\end{array}$ & $\begin{array}{l}\text { Some students indicated they would have } \\
\text { liked additional lecture time given the broad } \\
\text { scope of nutritional interventions and others } \\
\text { indicated additional practical exercises } \\
\text { would be beneficial. }\end{array}$ & $\begin{array}{l}\text { "I enjoyed the power point lecture and wished it could have } \\
\text { been longer" } \\
\text { "More focus on mechanisms of action" } \\
\text { "Considering the vast scope of nutrition and health, session was } \\
\text { a brief overview" } \\
\text { "Exemplar video examples of experts taking cases and providing } \\
\text { advice" } \\
\text { "Maybe less of a focus on research and more practical tips on } \\
\text { approaching weight loss with our patients" } \\
\text { "Best ways to convince people to change their diet" }\end{array}$ \\
\hline $\begin{array}{l}\text { Part 2: practical case } \\
\text { studies }\end{array}$ & $\begin{array}{l}\text { More students were in favor of the practical } \\
\text { applications over the research details. }\end{array}$ & $\begin{array}{l}\text { "More interactive activities and shorter lecture" } \\
\text { "Breaking up lecture with more activities to maintain interest" } \\
\text { "Spend more time doing cases" } \\
\text { "Case studies at the end were most useful. Not sure whether } \\
\text { these could be worked in throughout to be even more } \\
\text { interactive?" }\end{array}$ \\
\hline $\begin{array}{l}\text { Part 2: practical case } \\
\text { studies: subset who } \\
\text { participated in the } \\
\text { videotaped role plays }\end{array}$ & These sessions were generally well received & $\begin{array}{l}\text { "Really great, interactive, educational session" } \\
\text { "Very good"; "Interesting" } \\
\text { "I found this session much more interesting and applicable then } \\
\text { the first. I will try and eat better as a result of what I have } \\
\text { learned. Good session overall" }\end{array}$ \\
\hline
\end{tabular}

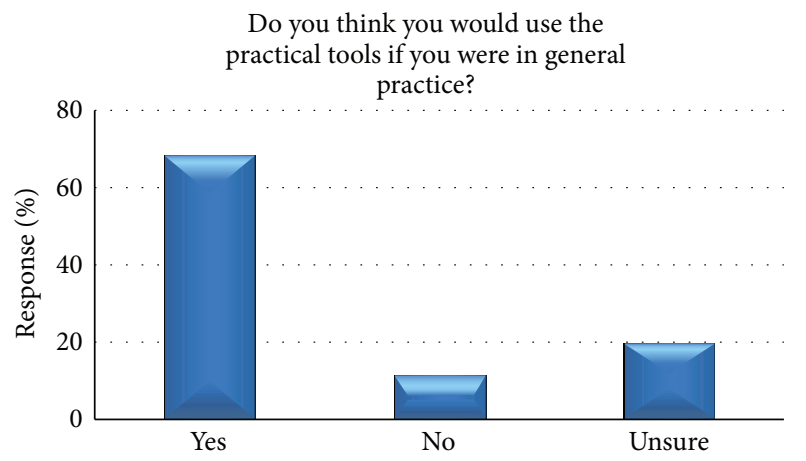

FIGURE 3: Clicker response system result from second series session.

current medical practice. In order to ascertain the importance students placed on their own food choices, they were asked whether they preferred or would likely choose either junk food or vegetable snack options. More students preferred junk food and only a small percentage of these indicated they would more likely choose healthier options. Considering that the majority of students documented that nutrition was an important part of healthcare, nutrition as such was not highly considered when selecting food choices. This disassociation of food consumption and health outcomes might be explained by the lack of emphasis of nutrition in their medical school curricula and also in current health care models. Another deliberation is the commonly large scale availability and low price point for unhealthy food choices. This in reflection with the sometimes limited budgets of medical students need also be considered.

It is well established that many blended learning techniques and activities might be useful in assisting students with the integration of knowledge and the development of deeper thought processes such as critical thinking and problem solving. Bloom's Taxonomy of Educational Objectives identifies these types of objectives as higher level intellectual processes such as analysis, synthesis, and evaluation [19]. This cohort found the practical application of the theoretical components to be beneficial to their learning and also conducive to their willingness to participate in the blended learning sessions.

Another important component is feedback, which is more than it is merely happening or not happening. Technologies such as "clickers" provide immediate responses to students as to the state of their current understanding of topics being discussed. Good practice gives prompt feedback which should happen reasonably soon after the learning activity [20]. What is needed for a lecture to be effective is for evidence on performance to be available at the time so corrections can be progressively made when necessary. The clicker technology is a useful method to provide this immediate feedback and also enhance student engagement.

Regular intervals which allow students to discuss previous material can help them to summarize and clarify related information before moving on [21]. As opposed to asking questions at the end of a lecture period, utilizing a step-bystep lecture method whereby the content is arranged into any number of short periods of exposition, followed by a class discussion has been shown to be more effective [22]. In this way students can also receive their own immediate feedback and gauge their understanding and progress through the subject material while keeping them motivated. If things are not clear at any stage in a learning process, it is better to resolve these issues before the problem becomes any more extensive.

Most of the students in the cohort were able to answer multiple choice questions correctly when they were positioned periodically throughout the lecture, which demonstrated their engagement with the theoretical lecture style 
content. This type of arrangement has been documented to lend its success to a number of additional variables along with the benefits of immediate feedback. These include the opportunity for rehearsal and the reduction of retroactive interference, along with the effect of a change of activity and stimulation on the potential decline of students' attention [22]. The students seemed overall in favor of the interactive nature of the sessions, some making comments about further integration of the practical component discussions throughout the initial background research lecture, to maintain their concentration and interest. Many suggested a greater interest in the "case studies" rather than the research and background theories. Those who participated in the video-taped role plays found the sessions to be most useful.

Limitations to this study included the inability to formally assess students on their actual content knowledge before and after the additional nutrition sessions. Summative evaluation of students' ability to perform a clinical nutritional assessment would have also been beneficial.

\section{Conclusions}

Favorable feedback was highlighted with the provision of nutrition education and also the utility of blended learning techniques to enhance student engagement. Importantly nutrition as the topic focus was deemed, by students, as essential to their education and also to healthcare practices. Integration of nutrition in medical education should enhance future primary care physicians' ability to recommend nutrition. The underlying processes should recognise nutrition as both being the cornerstone of preventative health and being vital to lowering the risk of chronic disease pathologies. Increasing this awareness, in both physicians and their patients, may assist in modifying treatment plans and allow for further health recommendations as opposed to being limited to drug types of therapy. The burden of rising health care costs as morbidity, prospective drug prescriptions, and their potential side effects, may also subsequently be reduced.

\section{Appendix}

\section{Online Nutrition Support Resources}

Australian Government Health Promotion websites are

(i) Australian Dietary Guidelines and support resources: http://www.eatforhealth.gov.au/,

(ii) Go for 2 \& 5 fruit and veggie ideas: http://www .gofor2and5.com.au/,

(iii) Happier Healthier nutrition and fitness: http://healthier.qld.gov.au/fitness/,

(iv) Better Health Channel: http://www.betterhealth .vic.gov.au/bhcv2/bhcarticles.nsf/pages/healthy_living ?open,

(v) Public Health Nutrition programs: http://www.public.health.wa.gov.au/2/1575/2/nutrition_and_healthy_ weight.pm.
Other healthy recipe sites to assist in ideas and menu planning are

(i) http://www.healthyfoodguide.com.au/,

(ii) http://www.betterhealth.vic.gov.au/bhcv2/bhcsite.nsf/ pages/bhc_recipes,

(iii) http://daa.asn.au/for-the-public/smart-eating-for-you/ recipes/browse/.

For kids sites are

(i) http://www.healthykids.nsw.gov.au/recipes.aspx,

(ii) http://healthy-kids.com.au/parents/recipes/,

(iii) http://kidshealth.org/kid/recipes/index.html.

Activity calorie counter site is

(i) http://www.8700.com.au/balance-and-burn/kj-activity-comparison/.

Consumer information site is

(i) http://www.foodstandards.gov.au/consumer/Pages/ default.aspx.

Nutrient reference values site is

(i) http://www.nrv.gov.au/.

Drug and supplement information site is

(i) http://www.nlm.nih.gov/medlineplus/druginformation.html.

\section{Conflict of Interests}

The authors declare that there is no conflict of interests regarding the publication of this paper.

\section{Acknowledgments}

Teaching, Education, and Scholarship of Learning (TESOL), The University of Queensland, provided start-up funding for this pilot project. Centre for the Discipline of Medical Education Research and Scholarship (CDMERS) provided follow-up funding for the project. Brown University allowed the adaptation and use of a standardized Australian version of their WAVE and REAP tools. Educational Innovation and Technology, UQ, provided support with "clicker" technology. University of Queensland Assessment Network (UQAN) provided mentoring support. Tracey Seipel and Nita Sharp are acknowledged for their teaching support.

\section{References}

[1] K. A. Tappenden, B. Quatrara, M. L. Parkhurst, A. M. Malone, G. Fanjiang, and T. R. Ziegler, "Critical role of nutrition in improving quality care: an interdiscipinary call to action to address adult hospital malnutrition," Journal of the Academy of Nutrition and Dietetics, vol. 113, no. 9, pp. 1219-1237, 2013.

[2] A. Minino and L. Smith, "Deaths: preliminary data for 2000," in National Vital Statistics Reports, 2001. 
[3] G. J. Hiddink, J. G. A. J. Hautvast, C. M. J. Van Woerkum, C. J. Fieren, and M. A. Van 't Hof, "Consumers' expectations about nutrition guidance: the importance of primary care physicians," American Journal of Clinical Nutrition, vol. 65, no. 6, pp. 1974S1979S, 1997.

[4] M. G. Stephenson, A. S. Levy, N. L. Sass, and W. E. McGarvey, "1985 NHIS findings: nutrition knowledge and baseline data for the weight-loss objectives," Public Health Reports, vol. 102, no. 1, pp. 61-67, 1987.

[5] US Department of Health and Human Services, "The surgeon general's report on nutrition and health," in The Reports of the Surgeon General, Nutrition Policy Board, Ed., Public Health Service, Office of the Surgeon General United States, 1988, http://profiles.nlm.nih.gov/NN/B/C/Q/G/.

[6] US Department of Health and Human Services and Public Health Service, Healthy People 2000: Progress Review; Nutrition, US Department of Health and Human Services, 1998.

[7] F. M. Torti, K. Adams, L. Edwards, K. Lindell, and S. Zeisel, "Survey of nutrition education in U.S. medical schools-an instructor-based analysis," Medical Education Online, vol. 6, p. 8, 2001, http://www.med-ed-online.org/res00023.htm.

[8] US Department of Health and Human Services and Public Health Service, Healthy People 2010 Objectives; Nutrition Counselling, US Department of Health and Human Services, Washington, DC, USA, 2000.

[9] USDHHS, Increase the Proportion of Physician Visits Made by All Child or Adult Patients That Include Counseling about Nutrition or Diet in 2020 Topics and Objectives, US Department of Health and Human Services, Washington, DC, USA, 2007, http://www.healthypeople.gov/node/4965/data_details.

[10] P. M. Brooks, "Undergraduate teaching of complementary medicine," Medical Journal of Australia, vol. 181, no. 5, pp. 275-277, 2004.

[11] M. A. Lyon, "Academic self concept and its relationship to achievement in a sample of junior high students," Educational and Psychological Measurement, vol. 53, no. 1, pp. 201-210, 1993.

[12] J. A. Box and D. Little, "Cooperative small-group instruction combined with advanced organizers and their relationship to self-concept and social studies achievement of elementary school students," Journal of Instruction Psychology, vol. 30, no. 4, pp. 285-287, 2003.

[13] M. H. Towns, K. Kreke, and A. Fields, "An action research project: student perspectives on small-group learning in chemistry," Journal of Chemical Education, vol. 77, no. 1, pp. 111-115, 2000.

[14] M. W. Jackson and M. T. Prosser, "Less lecturing, more learning," Studies in Higher Education, vol. 14, no. 1, pp. 55-68, 1989.

[15] F. A. Sojoka, "The need for hands-on science," Journal of College Science Teaching, vol. 22, no. 11, pp. 4-5, 1992.

[16] P. C. Schlechty, Inventing Better Schools. An Action Plan for Educational Reform, Jossey-Bass, San Fransisco, Calif, USA, 1997.

[17] T. A. Angelo and K. P. Cross, Classroom Assessment Techniques: A Handbook for College Teachers, Jossey-Bass, San Francisco, Calif, USA, 1993.

[18] K. M. Gans, E. Ross, C. W. Barner, J. Wylie-Rosett, J. McMurray, and C. Eaton, "REAP and WAVE: new tools to rapidly assess/discuss nutrition with patients," The Journal of Nutrition, vol. 133, no. 2, pp. 556S-562S, 2003.

[19] B. S. Bloom, Taxonomy of Educational Objectives, Longman, London, UK, 1972.
[20] A. W. Chickering and Z. F. Gamson, "Seven principles for good practice in undergraduate education," Wingspread Journal, vol. 9, special insert, no. 2, 1987.

[21] L. L. C. Jones, "Are lectures a thing of the past?" Journal of College Science Teaching, vol. 32, no. 7, pp. 453-457, 2003.

[22] D. Bligh, What's the Use of Lectures? Intellect, Bristol, UK, 1998. 

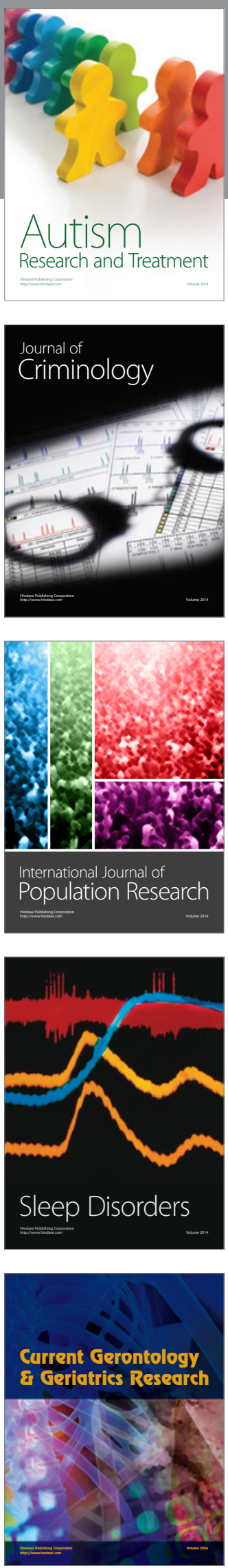
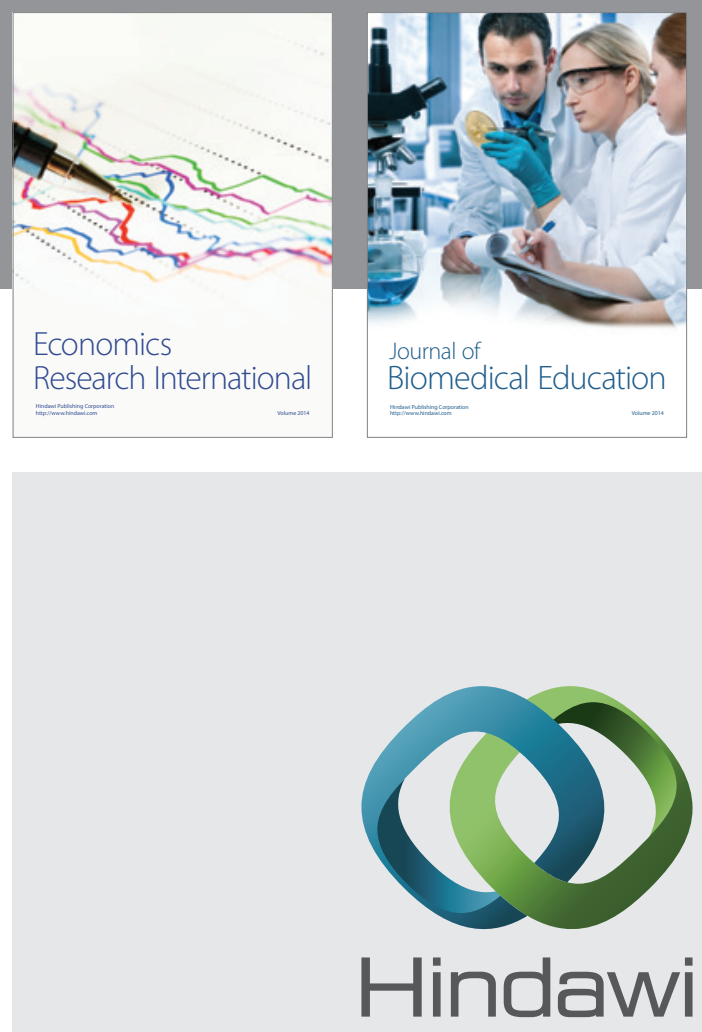

Submit your manuscripts at

http://www.hindawi.com
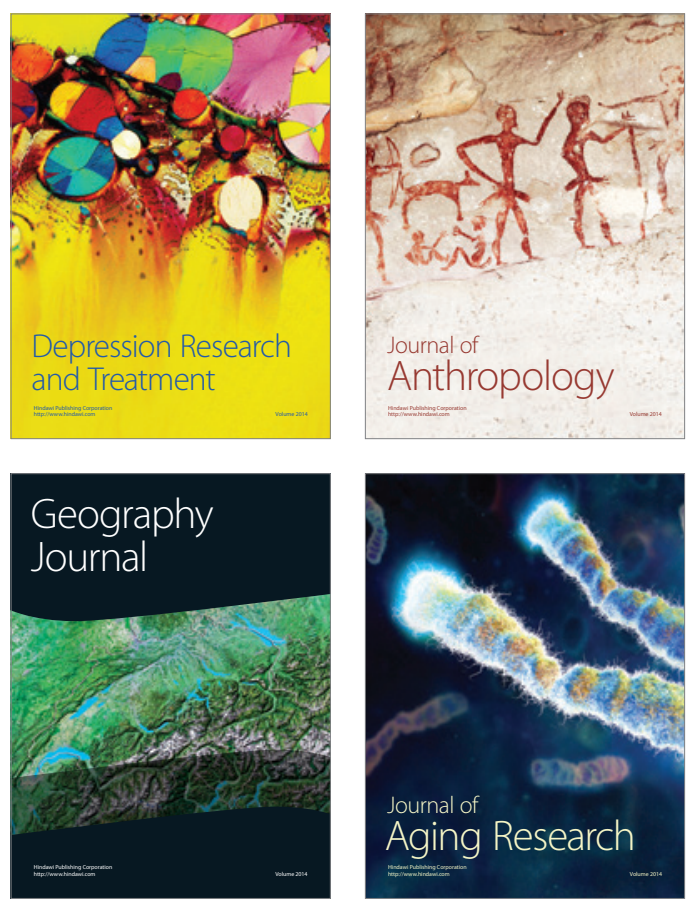
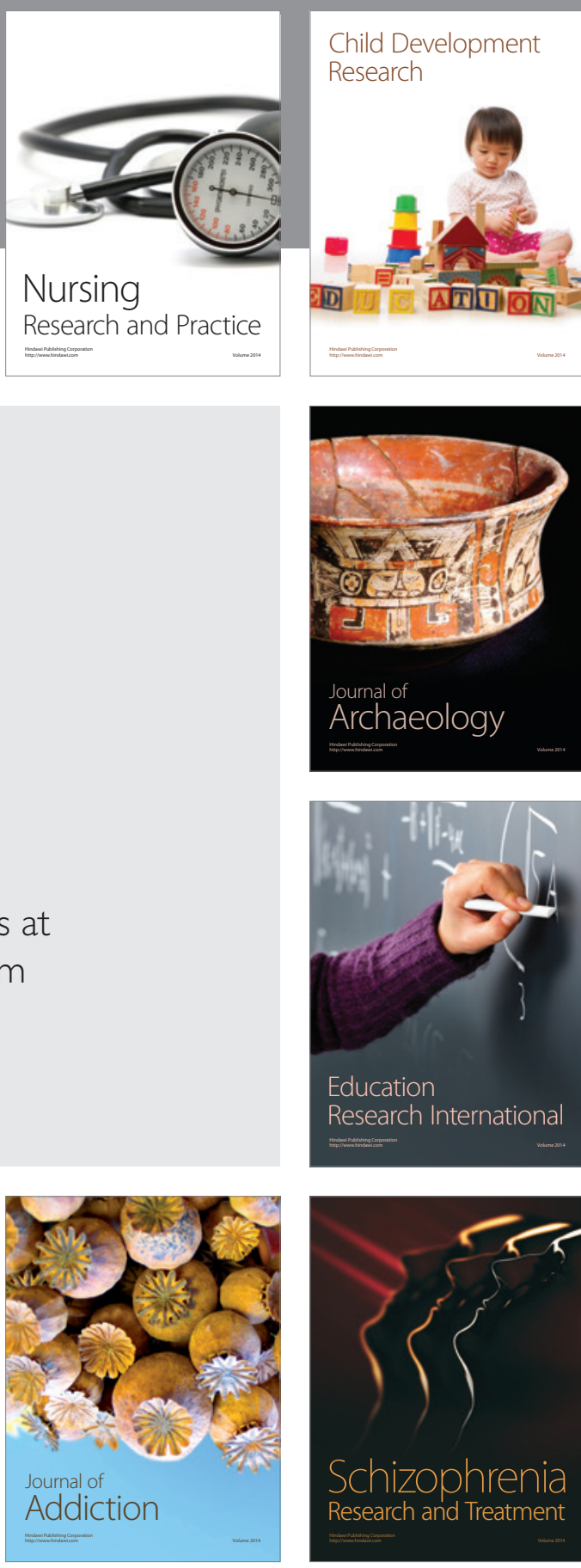

(D)
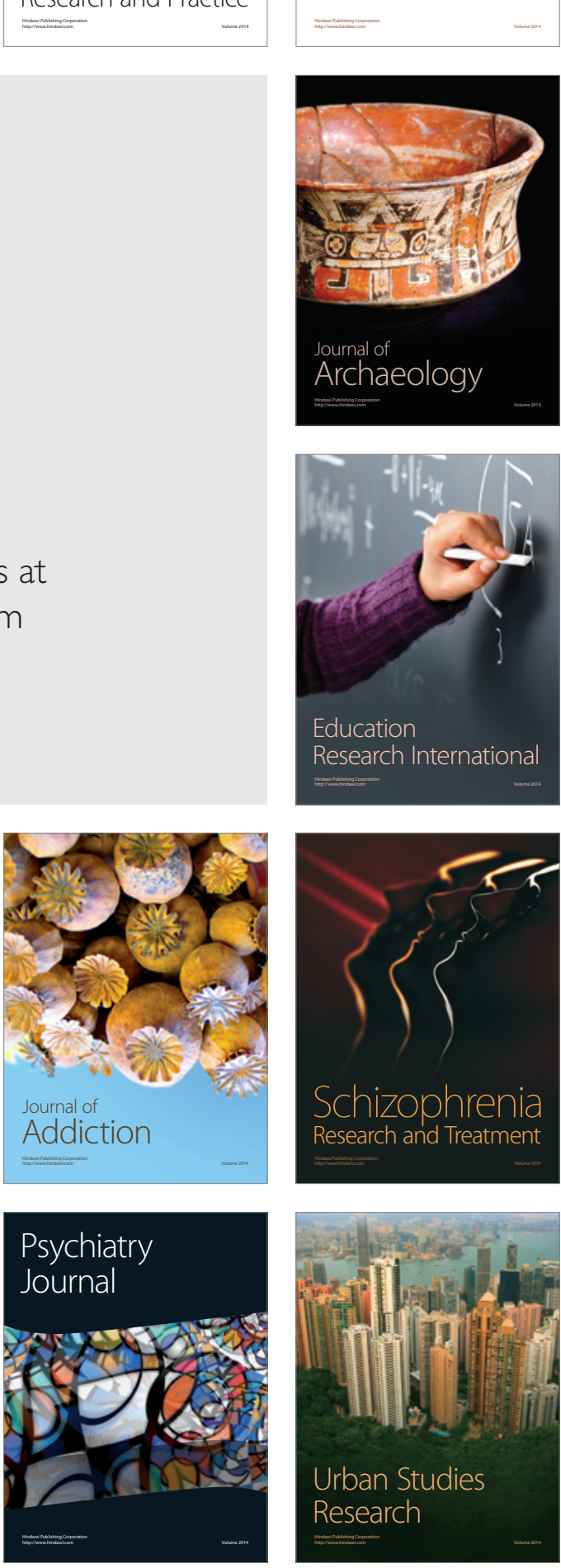